Mind reading:

Brain scan

resource paves

way for discovery

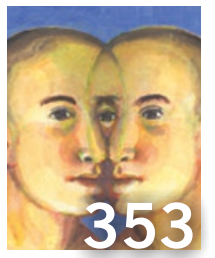

Single spectrum:

Are autism and

schizophrenia two

sides of the same coin?

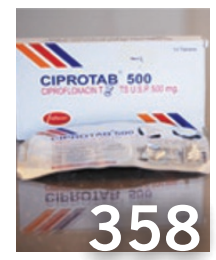

Fake out:

A focus section on

the deadly blight of

counterfeit medicines

\title{
Routine lab method's accuracy called into question
}

In 2002, four years after first sparking public controversy over whether the measles, mumps and rubella vaccine causes autism, Andrew Wakefield reported a possible molecular mechanism for the connection. $\mathrm{He}$ claimed that a form of irritable bowel disease, which he called autistic enterocolitis, was triggered by the measles virus (Molec. Pathol. 55, 84-90, 2002). That finding, however, was based on a "defective experimental technique," Stephen Bustin, a molecular biologist at Barts and the London School of Medicine and Dentistry, told a US federal court in 2007. The problem: Wakefield had incorrectly applied the common laboratory protocol known as quantitative real-time polymerase chain reaction ( $\mathrm{qPCR}$ ) to come to his conclusions.

Bustin says this faulty lab work is a problem shared by many researchers around the world who have turned to qPCR to measure gene expression. Unlike standard PCR, which can only crudely quantify levels of DNA, the chemistry behind qPCR allows researchers to assess such levels more precisely by comparing sequences of interest against a known reference added to the test tube mix as a control.

But the reference genes used in qPCR can vary between experiments and laboratories, which can give misleading results or make it difficult to compare one study to another. As a result of this and other variables in the technique, a majority of scientific papers involving qPCR include flawed methods, say a team of leading qPCR experts. Most qPCR methods, as reported in the literature, are improperly validated and irreproducible, Bustin claims.

Last year, he and 11 colleagues published a set of more than 60 individual standardscollectively called the Minimum Information for Publication of Quantitative Real-Time PCR Experiments (MIQE) - to address this problem (Clin. Chem. 55, 611-622, 2009).

"If you look at the literature, you find again and again and again the appalling quality of qPCR protocols," says Bustin, who this month repeated his call for the scientific community to adopt the MIQE guidelines
(Methods 50, 217-226, 2010). “There's no excuse for anyone either not reporting or not doing experiments properly."

The consequence of poor methodology is that many published papers contain erroneous conclusions, says Mikael Kubista, a coauthor of the MIQE guidelines and chief executive of the TATAA Biocenter in Göteborg, Sweden. "The problem is that the technique itself seems so simple and so easy to do, [but] in real life you're analyzing biological samples with complexity."

Wakefield's 2002 study reported the presence of measles virus in the gut, yet the authors hadn't included a reversetranscription step to convert the RNA virus into DNA in some of their qPCR runs, and so they probably detected a DNA contaminant, according to Bustin's testimony (Eur. Pharm. Rev. Dig. 1, 11-16, 2008). This error and others like it could be prevented by following correct methodology, Bustin says. The MIQE guidelines, for example, call for a detailed description of the reagents used in the technique, including the enzyme type used for the RNA reverse transcriptase step. (A follow-up publication that included the 2002 paper's corresponding author John O'Leary, of Trinity College Dublin, among others, used the same methods as the original study and found no link between measles and autism (PLoS One 3, e3140, 2008). Neither Wakefield nor O'Leary was available for comment.)

Not all researchers are convinced that the MIQE guidelines are the perfect solution. "There's no doubt that there is a need for improved standardization," says Helen Fernandes, director of molecular diagnostics at the University of Medicine and Dentistry of New Jersey in Newark, who is helping evaluate protocols for the Clinical and Laboratory Standards Institute, a global organization supporting consensus lab procedures. But "we have to consider other views or other guidelines, as well," she explains.

Many researchers might be reluctant to adopt the guidelines unless major journals first change their publication policies. Journal

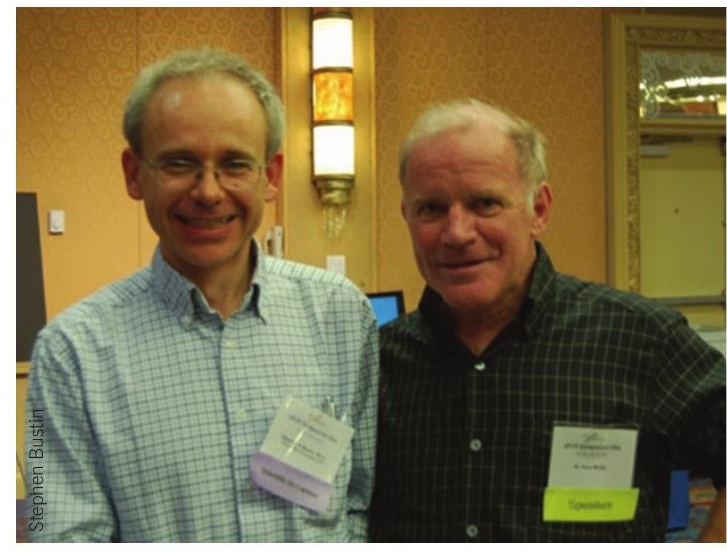

PCR proponents: Stephen Bustin (left) and PCR inventor Kary Mullis.

editors, however, are hesitant to impose new rules without a broader scientific consensus. "We would be delighted to embrace the [MIQE] guidelines, but we are not really persuaded that the guidelines are embraced by the community," says Juan Carlos López, editor-in-chief of Nature Medicine, which does not require that authors adhere to MIQE. This view is reflected in the policies of most leading journals, including Cell, Science, Nature, PLoS, New England Journal of Medicine and The Lancet, which do not mention qPCR data in their instructions for authors, although many have instructions for other common lab techniques such as DNA microarrays.

One publisher that has warmed to MIQE is London-based BioMed Central (BMC). Although adherence to the principles is not explicitly required of authors, BMC journal editors and reviewers use them to guide disputes over how qPCR data should be reported. "Where there has been methodological information lacking or issues raised about the quality of these particular experiments, it has been extremely useful to quote the MIQE guidelines," says BMC's senior scientific editor Scott Edmunds. However, BMC has no plans make the guidelines compulsory, he adds.

Catherine Shaffer, Ann Arbor, Michigan 